
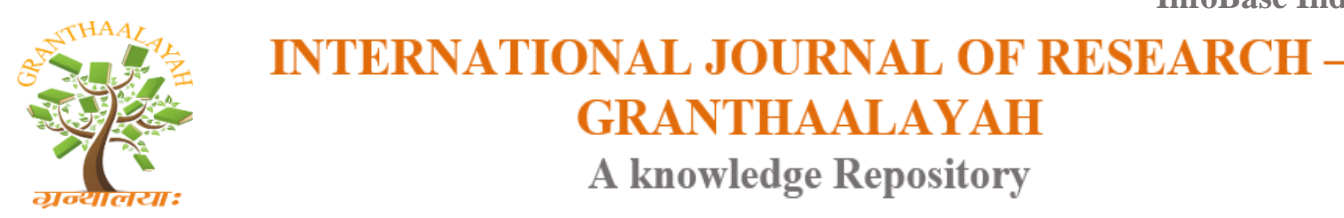

Management

\title{
INFORMATION SEEKING BEHAVIORS IN ELECTRONIC ENVIRONMENT
}

\author{
Varsha Bharadwaj $^{* 1}$, Dr. Javed Khan ${ }^{2}$ \\ ${ }^{* 1}$ Research Scholar, Swami Vivekanand Subharti University, Meerut, India \\ ${ }^{2}$ Associate Professor, Swami Vivekanand Subharti University, Meerut, India
}

DOI: https://doi.org/10.29121/granthaalayah.v4.i12.2016.2401

\begin{abstract}
Information is recognized as a vital sources and the basic need, for the progress of humanity and the development of a nation, as a whole. The availability of information in the electronic media has created an opportunity for global access to information. An electronic resources is defined as a resource which requires computer access or any electronic product that delivers a collection of data, be it tats referring to full text data bases, electronic journals, image collection, other multimedia products numerical, graphical or time based, as a commercially available title that has been published with an aim to market and resources are basically distribution of information in any electronic form such as CD-ROM, flop disk or magnetic tape or a closes a computer network like and journals E-book etc. The full length article highlight the use of electronic resources in different fields, types of e-resources, purpose and advantages and disadvantages of e-resources in context of information seeking behaviour.
\end{abstract}

Keywords: Information; Information Seeking Behaviour; E- Resources; Electronic Media.

Cite This Article: Varsha Bharadwaj, and Dr. Javed Khan. (2016). "INFORMATION SEEKING BEHAVIORS IN ELECTRONIC ENVIRONMENT." International Journal of Research Granthaalayah, 4(12), 132-136. https://doi.org/10.29121/granthaalayah.v4.i12.2016.2401.

\section{Introduction}

Information seeking behavior refers to those activities a person engages in when identifying his or her own need for information, searching for such information in any way and using or transferring of information. Information behavior is the totality of human behavior in relation to the sources and channels of information, including both active and passive information seeking and information use. Thus it includes face to face and online communication with others as well as the passive reception of information. Information seeking behavior involves personal reasons for seeking information, the kinds of information which are being sought and the ways and sources with which needed information is being sought. Information seeking behavior is 
expressed in various forms, from reading printed material to research and experimentation. Scholars, students and faculties actively seek current information from the various media available in libraries, for example encyclopedias, journals and more currently, electronic media.

\section{Information Seeking Process}

In order to satisfy the information needs, the user actively undergoes the information seeking process. The attempt of the user in obtaining the needed information is described as the information seeking behavior. The nature of information seeking behavior in information exchange process has been discussed by Willson as under:

\section{Influencing Factors}

The factors that influence the human seeking behavior include.
a) Payoffs and costs
b) Resources available
c) Update rates
d) Amount of information available
e) Diagnosticity of data
f) Distributional characteristics of data
g) Conflicts among sources

It may be emphasizes that a correct appraisal of information seeking behaviour implies knowledge of:

a) The purpose for which information is required.

b) Environment in which user operate

c) User's skill identifying information need and information provider's skill in providing information.

d) Channels and sources for taping the information, and

e) Barriers to information.

\section{Electronic Resources}

The electronic resources are systems in which information is stored electronically and made accessible through electronic systems and computer networks. These resources include OPAC, CD-ROMs, Online- Databases, E-journals E-books, Internet resources etc. Multiple accesses speed, richer in content, reuse, timeliness, anywhere access is some of the features of eresources. IEEE Explore, Elsevier Science Direct, ASCE Journals, ASME Journals, EBSCO, Springer, etc. are the example of some famous e-resources available in India and overseas. These resources are paid resources and only accessible after payment. These resources are only limited access. These are available in so many different packages in different price ranges. In India, these resources are available through INDEST-AICTE consortium and UGC-INFONET. Consortium on some discounted prices. Electronic resources provide access to information that might be restricted to the user because of geographical location or finances. Electronic resources also provide access to current information as these are often updated frequently. Through their various search techniques electronic resources provide extensive links to explore additional 
resources or related content. In addition, electronic resources are considered as important resources of teaching, research and training. Thus, most of libraries as well as the universities of the present day provide electronic resources for higher education and research.

\section{Purpose of E- Resources}

Main purpose of electronic resources is providing current information.

- Update information is necessary for research work.

- Through electronic resources users are able to access latest information.

- Save the time of user and staff

- Solve the space problem in library

- Easy to use and disseminate

\section{Need of Electronic Resources}

Electronic resources have great potential and bright future to attract users. It combines all the benefits of the multimedia, digital coding and Internet. It enable user to carry everywhere and can be read on all types of computers including handled device.

- E- Resources can be downloaded instantly.

- Users can read an e- resource any time

- Due to portability, e-resources can be taken anywhere on portable computer.

- Font size can be changed suitably;

- E- resources provide facility to hold and turn pages easily

- Physically disabled users can hear audible E- resources

- In buying E- resources, the overhead charges like shipping, postal ,handling are totally ruled out

\section{Type of E-Resources}

- E-Books

- E-Journals

- E-Magazine

- E-Bibliographic Databases

- E-Audio / visual resources

- E-Images

- E-Thesis and dissertation (ETD)

- E-News Papers

- Data bases

- E-Data archives

- E-Manuscripts

- E-Maps 


\section{Features of E-Resources}

1) Text can be searched, except when represented in the form of images;

2) Hundreds or thousands may be carried together on one device. Approximately 500 average e-books can be stored on one CD;

3) Type size and type face may be adjusted

4) E- Resources can be used with text-to-speech software;

5) Distributed at low cost;

6) Distributed instantly, allowing readers to begin reading at once, without the need to visit a bookstore.

7) No risk of damage, vandalism, etc. on the pages

\section{Advantages of E-Resources}

There are many advantages of e-resources due to their special characteristics and now eresources are becoming very familiar among users. The following are main advantages of eresources:

- Many users many access same resources over computer system in sometime.

- Accessible- can be accessed from any computer on campus and usually any computer off campus, any time of the day and night, so there is no need to make a trip to the library.

- Easily searchable- each journal can be searched quick and easy often through the complete full text of articles and via online index.

- Speed- articles / issues appear online before printed version is available.

- Interactive- Rapid turnaround times means articles can be read, commented by the readers, amended quickly and grater feedback thru the web.

- Preservation of these resources is very easy and user many save these resources on their pen drive or storage devices and later may access e-resources on their computer systems and laptop etc.

- Links- hypertext format should be exploited and links to related articles, information on other websites, stable URLs for individual articles and e-mail alerts when latest issue loaded.

- Inexpensive- saving can made over printing costs, disturbing costs and extra costs by new feature.

\section{Disadvantages of E-Resources}

As is one side there are many benefits of e-resources on the other side the following are the drawbacks of e-resources:

- Those have week eye vision and continue reading computer screen is not possible and this put stress on eyes.

- We may read books in any position but there are many limitations on computer monitor.

- Books remain always till the physical damage of it but much information on screen becomes obsolete / inaccessible very speedily.

- Many times, many e-resources are not including in indexing and abstracting services and these create problems for users. 
- Without light and internet connection e-resources are waste but we may read books in natural light and without net connection.

- Many times legal issues are unknown to users.

- Format of e-resources become obsoleted and users are unable to read these over computer and on net.

\section{Conclusion}

The information plays vital role in this digital environment. This has become because of the technological advancements and changing information needs of the users. Technology has dominated all spheres of human activity and the libraries are not and exception one. The availability of information in the electronic media has created an opportunity for global access to information. E-resources are very important in the current electronic era as per requirements of the users of libraries due to easy accessible / searchable nature of e-resources. E-resources are nothing but digital collection meant to provide solution to regular and control the fast rating information explosion in then the recent year. More ever electronic recourses consist of materials that are computer controlled including materials that requires the use of a peripheral attached to computer. and resources are those resources, which is stored electronically and that can be accessible through electronic system and networks there are several types of electronic resources available and these e-resources consists of wide varieties of materials includes information in any electronic form such as CD-Rom, online, data bases, e-Journals e-books, ETD, OPACS, internet resources and any type of digital resources. Nature and shape of e-resources are changing very fast and this creates challenges to library manager in the concern of preservation and maintenance of e-resources.

\section{References}

[1] Dadzie, P.S. (2005) Electronic resources: Access and usage at Asheshi University College. Comp. Wide Inf. Sys, 22(5), 290-97.

[2] Poonam R.P (2016) "E-Resources in libraries: A theoretical concept" 2nd National Conference library information science and information technology for education. 22 (6) p 204-207.

[3] Singhal K.P. and Gautam J.N. (2005) Information seeking behavior of PG Students studying in Professional courses (MM (PG) College, Modinagar) and study with reference to their library use, library heraid.43 (2); 92-108.

[4] Wilson, T.D (1999). Models in information behaviour in research Journal of Documentation 55 (3): 249-270.

*Corresponding author.

E-mail address: javedsaim@gmail.com 